Original article

\title{
Parental Family Violence and Mental Health among parents and their offspring in the Southern Province, Rwanda
}

Thérèse Uwitonze ${ }^{1}$, Japhet Niyonsenga ${ }^{1 *}$, Emmanuel Habumugisha ${ }^{2}$, Ignatiana Mukarusanga $^{1}$, Jean Mutabaruka ${ }^{1}$

${ }^{1}$ Department of Clinical Psychology, College of Medicine and Health Sciences, University of Rwanda

${ }^{2}$ Rwanda National Commission for Children, Kigali, Rwanda

*Corresponding author: Japhet Niyonsenga, Department of Clinical Psychology, College of Medicine and Health Sciences, University of Rwanda.Email: niyonsengajaphet74@gmail.com

\section{Abstract}

\section{Background}

Children who witness violence between parents have an elevated risk of developing mental disorders as well as being victims or perpetrator of family violence $(\mathrm{FV})$ in their future relationships when compared with children from non-violent family.

\section{Objectives}

To assess links between both parental FV and mental disorders, and mental disorders in their offspring.

\section{Methods}

One hundred and thirty eight (138) participants dispatched in two categories: spouses/partners (N: 89; 40 Males) and offspring (N: 49; 20 Males) have been recruited from eight District Police Unities (DPU) of the Rwandan Southern Province to participate in this cross-sectional study during a 7 months period. This study used the student " $t$ " to examine the links between parental FV and mental disorders in offspring.

\section{Results}

Parental FV was linked with PTSD, psychopathic and addiction behavior symptoms in offspring. Parental anxious attachment was linked with anxiety and addiction behavior symptoms in offspring and the risk of being perpetrator or victims of FV. Parental avoidant attachment was linked with depression symptoms in offspring. Further, both parental low self-esteem and PTSD were linked with depression and PTSD symptoms in offspring. 


\section{Conclusion}

The results indicate that FV and mental disorders experienced by parents seem to affect offspring's mental health and generate specific mental disorders. Therefore, the intervention programs should focus on the treatment of both parental and children mental disorders.

Rwanda J Med Health Sci 2020;3(3):291-314

Keywords: Family Violence, mental disorders, parents and offspring

\section{Background}

Although society tends to think of the family as a relatively safe place, a safe harbor and a place of care where spouses love each other and their children, families are often a source of child abuse, sibling abuse, abuse of parents, dating abuse, spouse abuse, and elder abuse. The World Health Organization (WHO) defines family violence $(\mathrm{FV})$ as: “any behavior within a family that causes physical, sexual or psychological harm, including acts of physical aggression, sexual coercion, psychological abuse and controlling behaviors".[1]

On a global scale, one-third of women (35\%) which corresponds to 818 million women have experienced either physical or sexual Intimate Partner Violence or non-partner sexual violence at some point of their lifetime.[2] FV is more prevalent in
Africa (37\%) and South-East Asia $(38 \%)$ than in Europe (25\%) and the Americas (30\%).[2,3]

In Sub-Saharan Africa, more than $75 \%$ of woman beating is justified, for example, when a woman is considered as not meeting her husband's and society's expectations.[3,4]

In Rwanda, a survey conducted in 2010 revealed that more than $50 \%$ of female respondents reported having experienced FV, while $38 \%$ of male respondents had perpetrated FV.[5,6] Relatedly, there are significant numbers of clinical cases of family members who have beaten up (murdered) each other or undergone any kind of abuse in their families.

Considerable authors have found that $\mathrm{FV}$ is associated with significant 
mental disorders in family violence to relieve the physical and members. $[7,8]$

emotional pain of abuse.[14]

More worryingly, over $75 \%$ of violent

The literature highlights that the behaviour in the family occurs in the individuals who are victims of family presence of children,[15] which is violence may develop mental disorders often associated with serious risk for and the ones who have mental long-term physical and mental health problems have an increased risk of problems, and social adjustment perpetrating FV. On the one hand, problems in children.[16] studies on mental and physical impact of $\mathrm{FV}$ on survivors revealed that exposure to FV increased the risk of mental illness, alcohol and drug abuseand poor physical health problems, $[9,10]$ but on the other hand, scholars found that mental disorders such as schizophrenia-spectrum disorders, bipolar disorder, depressive disorder, anxiety disorder, alcohol use disorder, drug use disorder, ADHD and/ or personality disorders in men were associated with a 2-8 times higher risk of $\mathrm{FV}$ against women (compared with the general population), and a 2-4 times higher risk of FV when compared with unaffected siblings.[11-13]

Furthermore, alcohol and other drugs may also be used by victims of family

Although the offspring who witness violence between parents may also be at greater risk of poor outcomes in their future relationships, the impacts on male and female children are different. For instance, a boy who witnesses his mum being abused is ten times more likely to perpetrate FV against his wife as an adult, but a girl who lives in the same condition is 6 times more likely to be sexually abused than one who lives in a nonabusive family.[17]

Scholars revealed three forms of child victimization in cases of $\mathrm{FV}$ such as "direct child abuse, exposure to FV, and the co-occurrence of child maltreatment and exposure to FV".[15] The current study focused on children exposed to family violence 
between their parents to further our understanding of the adverse effects of parental family violence and parental mental disorders on children's mental health.

In a meta-analysis of 118 studies, authors found that $63 \%$ of children who had witnessed family violence had poor mental health outcomes,[18] because these children are often affected by family problems and violence as one of environment factors[19] and inherited mental disorders from parents, for example PTSD.[20] Common mental disorders identified in children exposed to FV are PTSD, depression, and anxiety symptoms that have been connected with chronic diagnoses and health risk behaviours.[21,22] They often report more mood swings, feeling fear, despair, anger, frustration, shame, insecurity, self-blame and low selfesteem as compared to non-exposed children.[15,21] Further, it was found that adolescent offending and aggression were associated with seen suffering from significant mental childhood/adolescents' experience of health problems in our daily practices. parental violence. $[23,24]$
However, the severity and longevity of the effects of parental mental disorders and family violence on offspring are determined by the nature, severity and extent of those problems and accessibility of protective factors. Offspring's responses within families are different; some offspring are able to involve in supportive and nurturing environments despite the presence of parental problems, others will not be able to cope with family violence at all and hence become more affected.

Overall, the literature on transmission of parental mental disorders to children suggested that possible mechanisms of the general vulnerability to the development of mental disorders in children are mediated by both genetic and environmental factors. In Rwanda, more efforts have been put on mental health of women who had experienced $\mathrm{FV}[5,6]$ but a little is known about the mental health of the offspring who lives in violent family while they are 
Therefore, the objectives of this study were twofold. Firstly, this study aimed to identify a link between parental family violence and mental health problems in offspring. Secondly, this study sought to identify a link between parental and offspring mental health problems. We hypothesized links between parental family violence and Post-Traumatic Stress Disorder (PTSD), addiction behavior, anxiety, psychopathy, and depression symptoms and attachment styles in offspring. We further hypothesized links between (a) Parental anxious attachment and children anxiety symptoms; (b) Parental avoidant attachment and children depressive symptoms; (c) Parental low self-esteem and children depressive symptoms; (d) parental and children PTSD symptoms.

\section{Methods}

\section{Design}

This study used a cross-sectional study design to assess links between Family Violence and Mental Health problems among parents and offspring at the Anti-Gender based violence $\&$ Child Protection Program of
Police in south of Rwanda. The study period was of seven months from midMay to mid-December 2017.

\section{Participants' recruitment}

A total of 138 participants dispatched in two categories: spouses/partners (N: 89; 64\%; 40 males) and offspring (N: 49; 36\%; 20 males) from all eight District Police Unities (DPU) in south of Rwanda have participated in this study according to the Daniel's formula:

$\mathrm{n}=\frac{z^{2} p(1-p)}{d^{2}}=\frac{(1.96)^{2} 0.1(1-0.1)}{(0.05)^{2}}=138.2976 \approx$ 138 Where $\mathrm{n}=$ sample size, $Z=Z$ statistic for a level of confidence, $\mathrm{P}=$ expected prevalence or proportion, and $d=$ precision.[25] The age range was 16-17 years for offspring and 3467 years for spouses. Inclusion criteria were to be (i) a spouse or an offspring from violent family attending to Anti-Gender Based Violence and Child Protection Program of Police and (ii) children aged 16-17 who had witnessed parental FV at least one year. All participants voluntarily accepted to participate in this study. 


\section{Measures}

Two data collection tools were used in this study, one for spouses and another for offspring. The data collection tool for spouses had five sections such as sociodemographic characteristics, a self-constructed Likert questionnaire assessing family violence factors, the Rosenberg SelfEsteem Scale,[26] the PTSD Symptoms Scale-interview DSM-5,[27] and the experience in close relationships-revised (ECR-R) questionnaire.[28] However, the data collection tool for offspring included the 20-item Center for Epidemiological Studies Depression Scale for Children (CES-DC),[29] the Triarchic Psychopathy Measure (TriPM),[30] the Alcohol, Smoking and Substance Involvement Screening Test (ASSIST),[31] and the 66- item revised version of the Screen for Child Anxiety Related Emotional Disorders (SCARED-R).[32]

For parents, section one assessed the sociodemographic characteristics with six items; age, forms of marriage,

occupation and place of residence. factors and family-social factors. The

These variables were measured using frequencies (Table 1).

Section two was a 38-items selfconstructed Likert questionnaire assessing Family Violence factors.

The items are rated on four point Likert scale ranging from false (1), somewhat false (2), somewhat true (3) to true (4).

This questionnaire was generated from family violence theories by a deductive process from theories, variables, components and finally to indicators. Each item of the questionnaire had its corresponding indicator, therefore, the number of items were equivalent to that of indicators.

This study constructed its own Family Violence questionnaire because it needed a theory-based and inclusive questionnaire and that also contains adapted items to the study context. This study used a factors analysis to assess the structure of this questionnaire and found a coherent structure made up of individual 
Cronbach's alpha was 0.80 in our one intrusion symptom, one sample.

Section three was the Rosenberg SelfEsteem Scale,[26] a 10- item selfreported measure that assessed spouses' general self-worth in this study. It included five positive statements and five negative statements concerning a person's sense of self-respect and value. Each item was rated on a four-point Likert scale ranging from 1 (strongly agree), 2 (agree), 3 (disagree) to 4 (strongly disagree). The total score ranged from 0 to 30 , and 30 indicated the highest self-esteem. The Cronbach's alpha was .70 in our sample.

Section four was the PTSD Symptoms Scale-interview DSM-5 which was used to make a PTSD diagnosis and assess the severity of symptoms.[27]

The severity of symptoms were rated on a five-point Likert scale ranging from $0=$ not at all; $1=$ once per week or less/a little to 6 or more times a week/severe. The PTSD diagnosis was determined by counting the number of symptoms endorsed per symptom cluster. To meet diagnostic criteria avoidance symptom, two cognition and mood symptoms, and two arousal and reactivity symptoms were needed. The duration of more than one month (criterion F) and clinically significant distress or impairment (criterion) were also required.

The totaling the 20 PSS-I-5 symptom ratings determined the PTSD. The total score ranged from 0 to 80 . The Cronbach's alpha was .91 in our sample.

Section five was the experience in close relationships-revised (ECR-R) questionnaire[28] which was a 36item measure of adult attachment style. The ECR-R measured individuals on two subscales of attachment: Avoidance (i.e. Items 19 36) and Anxiety (the first 18 items). To obtain a score for attachment-related anxiety, we take an average of person's responses to items $1-18$ and for attachment-related avoidance, we took an average of a person's responses to items $19-36$.[28]

Higher scores on the Anxiety and Avoidant subscales indicate higher 
levels of attachment anxiety and for all other substances: 0-3: Low attachment avoidance, respectively. Risk, 4-26: Moderate Risk, 27+: High The Cronbach's alpha for anxious and Risk. For any substance, a score of 27 avoidant attachment was .75 and .74 or higher suggests a high risk of respectively in our sample.

For children; Section one was the 20item Center for Epidemiological Studies Depression Scale for Children (CES-DC) self-report measure that evaluated depressive symptoms in children aged 6-17 years. All items were scored as: $0=$ not at all, $1=\mathrm{a}$ little, $2=$ some, $3=\mathrm{a}$ lot except foritems $4,8,12$, and 16 scored as: 3 $=$ not at all, $2=\mathrm{a}$ little, $1=$ some, $0=\mathrm{a}$ lot. Total scores ranged from 0 to 60.[29] The Cronbach's alpha was .87 in our sample.

Section two was the Alcohol, Smoking and Substance Involvement Screening Test (ASSIST). The ASSIST was a ten classes used to detect and manage substance use and related problems in primary and general medical care settings.[31]

The ASSIST total score is obtained by summing questions' scores. For Alcohol, the scores are interpreted as following: 0-10: Low Risk, 11-26: Moderate Risk, 27+: High Risk, and dependence on that substance for a patient. The Cronbach's alpha was .71 in our sample.

Section three was the 66-item revised version of the Screen for Child Anxiety Related Emotional Disorders (SCARED-R).[32] The SCARED-R was a self-report questionnaire that assessed the symptoms of panic disorder, generalized anxiety disorder, social phobia, separation anxiety disorder, obsessive compulsive disorder, post-traumatic stress disorder and specific phobias in children aged from 8 to 17.[32] Items are rated from 0 (never) to 2 (often). Total score and sub-scores can be obtained by adding up relevant items (i.e. items of total scale or subscales). A total score of $\geq 25$ indicated the presence of an Anxiety Disorder.[32] Cronbach's alpha was .95 in our sample.

Section four was the 58-item Triarchic Psychopathy Measure (TriPM). TriPM was a self-report questionnaire that 
assessed psychopathy and concerns of three distinct phenotypic constructs: boldness, meanness and disinhibition. Separate subscale assessed a construct and subscale scores are summed to yield a total psychopathy score .[33] Items 2, 4, $10,11,16,21,25,30,33,35,39,41$, $44,47,50,52,57$ are coded as follows: true $=0$; somewhat true $=1$; somewhat false $=2 ;$ False $=3$. All other items are coded as follows: True $=3$; somewhat true $=2 ;$ somewhat false $=1 ;$ False $=$ 0 . Although the age ranges for the TriPM used to be 18 years and older,[30] the recent study of its construct validity on non-forensic sample in Italy found that the measure had excellent reliability and was minimally influenced by age and education.[34] Also the ages of children (i.e. 16-17 years) were much close to formal 18 years. The Cronbach's alpha was .71 in our sample.

\section{Tool translation}

This study applied the Brislin's backtranslation method for the translation of the data collection tools. [35] Firstly, four English-Kinyarwanda speaking clinical psychologists translated the version that had been adapted from the English (a) into Kinyarwanda (A). Secondly, the "consensus" version (A) was back-translated by two other bilingual persons, who had no previous knowledge of the original. After which a general agreement was found for each item of the Kinyarwanda (A) version.

\section{Data collection}

Spouses and children were invited and approached to participate in this study at the Anti- Gender based violence $\&$ child protection program of Police in eight District Police Unities (DPU) of the Rwandan Southern Province (Huye, Gisagara, Nyanza, Nyaruguru, Nyamagabe, Ruhango, Kamonyi, Muhanga). The study objectives and other pertinent information were clearly explained to the participants in the meeting room, and they were reassured that their responses would be confidential, anonymous, and that they could withdraw at any time.

All participants have provided written consent forms before data collection. The investigator was there to help 
illiterate participants by reading the question and recording the participant's selected response.

\section{Data analysis}

Statistical analysis was conducted using " $t$ " of Student for independent samples to assess links between family violence and mental health status of the offspring. The model assumes that a difference in the mean score of the dependent variable is found because of the influence of the independent variable that distinguishes the two groups (Parents and offspring).

\section{Ethical considerations}

Permission to conduct this study was obtained from the Institutional Review Board of the University of Rwanda, College of Medicine and Health Sciences. Additionally, regional Commissioner of Police/Rwandan Southern Province had provided permission to conduct the study in their setting. All participants signed the consent and assent forms prior to data collection.

\section{Results}

Sociodemographic characteristics of the 138 participants were presented. The majority were selected from DPU of Huye (40.6\%), followed by Gisagara $(24.6 \%)$ and the minority were selected from DPU of Nyanza (1.4\%, Figure 1).Almost all participants were cultivators $(63 \%)$ followed by students $(24.6 \%)$ and the least was traders $(0.7 \%$, Table 1$)$. The majority were females (56.5) and married $(64 \%$, Table 1). Of those married, the majority were legally married (76.4\%). Figure 1 percentage of participants in each District Police Unity

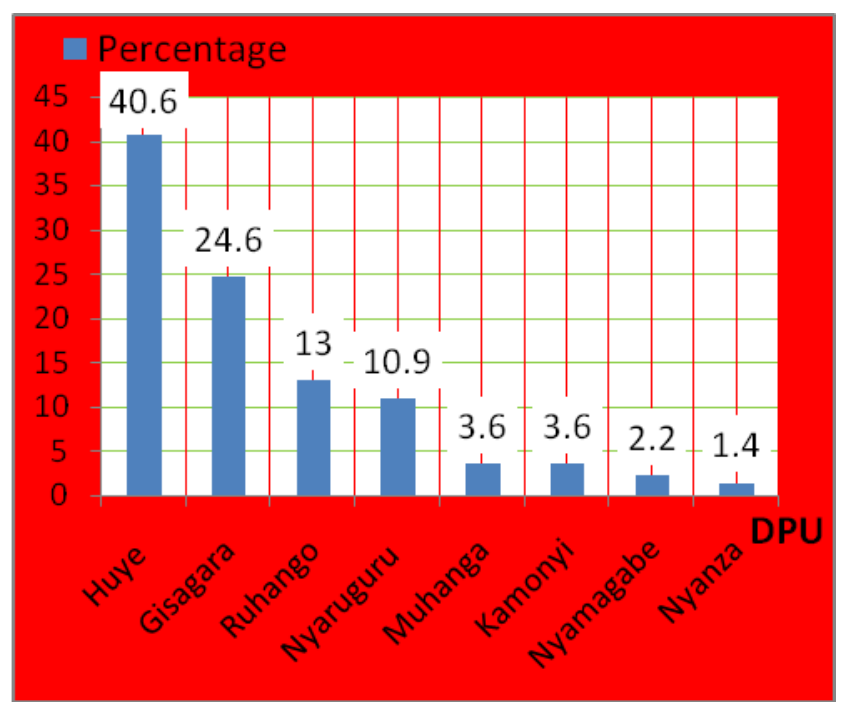

The spouses had experienced different forms of violence: psychological violence (37\%), economical violence (29\%), physical violence (26\%), and 
sexual violence (8\%). The results number was the ones who had showed that the numbers of those experienced two forms of violence who faced all forms of violence were (41\%).

$7 \%$ of the whole sample and the high

Table1. Socio-demographic characteristics $(n=138)$

\begin{tabular}{lc}
\hline Variable & n (\%) \\
\hline Age & \\
16 & $44(32)$ \\
17 & $7(5)$ \\
$32-38$ & $12(8.6)$ \\
$39-45$ & $21(15.5)$ \\
$46-52$ & $28(20)$ \\
$53-59$ & $18(13)$ \\
$60-67$ & $8(5.8)$ \\
Marital status & \\
$\quad$ Single & $49(36)$ \\
$\quad$ Married & $89(64)$ \\
Forms of marriage & \\
$\quad$ Illegal marriage & $68(76.4)$ \\
$\quad$ Legal marriage & $21(23.6)$ \\
Occupation & \\
$\quad$ Cultivators & $87(63)$ \\
$\quad$ Students & $35(26)$ \\
$\quad$ Unemployed & $6(4)$ \\
$\quad$ Traders & $3(2)$ \\
$\quad$ Others & $7(5)$ \\
Forms & \\
violence(FV) & \\
$\quad$ Psychological violence & $51(37)$ \\
$\quad$ Physical violence & $40(29)$ \\
$\quad$ Economical violence & $36(26)$ \\
Sexual violence & $11(8)$ \\
$\quad$ All forms of FV & $10(7)$ \\
$\quad$ Two forms of FV & $57(41)$ \\
\hline
\end{tabular}

\section{Prevalence of mental disorders in spouses and offspring}

Spouses had elevated clinical levels of PTSD symptoms (65.17\%), low self-esteem (46.1\%), anxious attachment (57\%) and avoidant attachment (43\%). About the psychopathy, the offspring with boldness, meanness and disinhibition symptoms were $41 \%$, $22 \%$, and $37 \%$ respectively. Offspring also had clinically levels of symptoms of depression (86\%), anxiety (92\%), PTSD (46\%) and addiction behavior: (47.4\%) for alcohol use and $52.6 \%$ for other drug use. 
Links between family violence and violence and mental health status of mental disorders among parents offspring. Family Violence was and the mental health dysfunction associated with PTSD symptoms of offspring $(\mathrm{t}=19.76, \quad \mathrm{p}<.001), \quad$ psychopathic symptoms $\quad(\mathrm{t}=5.97 ; \quad \mathrm{p}<.001), \quad$ and

This study supposed links between addiction behavior $(\mathrm{t}=15.91 ; \mathrm{p}<.001)$ parental family violence and Post- in offspring. Furthermore, links were Traumatic Stress Disorder (PTSD), detected between parental anxious addiction behavior, anxiety, attachment and anxiety symptoms in psychopathy, and depression offspring $(\mathrm{t}=7.42 ; \mathrm{p}<.001)$, parental symptoms and attachment styles in avoidant attachment and depression offspring. This study also symptoms in offspring $(t=17.83$; hypothesized links between (a) $\mathrm{p}<.001$ ), parental anxious attachment Parental anxious attachment and of parents and addiction in offspring children anxiety symptoms; (b) $(\mathrm{t}=16.11 ; \mathrm{p}<.001)$, parental low selfParental avoidant attachment and esteem and depression symptoms in children depression symptoms; (c) offspring ( $\mathrm{t}=-5.06, \mathrm{p}<.001)$, parental Parental low self-esteem and children low self-esteem and PTSD symptoms depression and PTSD symptoms (d) in offspring ( $\mathrm{t}=7.75, \mathrm{p}<.001)$, and parental and children PTSD parental and children PTSD symptoms. Using " $t$ " of Student, we symptoms $(t=9.43, p<.001)$ (Table 1 ). found links between parental family 
Table 1. Links between Family Violence, mental disorders among parents and the mental health dysfunction of offspring

\begin{tabular}{|c|c|}
\hline Variables & $\begin{array}{l}\text { "'t" of student } \\
\text { and } p \text { values }\end{array}$ \\
\hline $\begin{array}{l}\text { Family violence and Psychopathy symptoms } \\
\text { among offspring }\end{array}$ & $\mathrm{t}=5.97 ; \mathrm{p}=.000000$ \\
\hline $\begin{array}{l}\text { Family violence and PTSD symptoms among } \\
\text { offspring }\end{array}$ & $\mathrm{t}=19.76 ; \mathrm{p}=.000$ \\
\hline $\begin{array}{l}\text { Family violence and addiction behavior among } \\
\text { offspring }\end{array}$ & $\mathrm{t}=15.91 ; \mathrm{p}=.000$ \\
\hline $\begin{array}{l}\text { Parental avoidant attachment and depression } \\
\text { symptoms among offspring }\end{array}$ & $\mathrm{t}=17.83 ; \mathrm{p}=.000$ \\
\hline $\begin{array}{l}\text { Parental low self-esteem and PTSD symptoms } \\
\text { among offspring }\end{array}$ & $\begin{array}{l}\mathrm{t}=7,75 \\
.000000\end{array}$ \\
\hline $\begin{array}{l}\text { Parental anxious attachment and anxiety among } \\
\text { offspring }\end{array}$ & $t=7.42 ; p=.000000$ \\
\hline $\begin{array}{l}\text { Parental anxious attachment and addiction among } \\
\text { offspring }\end{array}$ & $\mathrm{t}=16.11 ; \mathrm{p}=.000$ \\
\hline $\begin{array}{l}\text { Parental low self-esteem and depression } \\
\text { symptoms among offspring }\end{array}$ & $\begin{array}{l}\mathrm{t}=-5.06 \\
\mathrm{p}=.000000\end{array}$ \\
\hline $\begin{array}{l}\text { Parental PTSD symptoms and PTSD symptoms } \\
\text { among offspring }\end{array}$ & $(t=9.43, p<.001)$ \\
\hline
\end{tabular}

\section{Discussion}

The current study had two main objectives: 1) to identify links between parental family violence and mental health problems in offspring and 2) to examine links between parental and offspring mental health problems. Our study indicated two main findings about the development of mental disorders in offspring living in violent families.

Firstly, our findings showed that family violence was significant associated with psychopathy, PTSD symptoms and addiction behavior in offspring. Regardless of the impacts of parental mental disorders on offspring, our findings suggested that children exposed to parental family violence may have an increased risk of developing psychopathy, PTSD and addiction behavior (i.e. alcohol and drug abuse).

As psychopathy is the combination of personality disorder traits related to criminal and other antisocial behaviors, the children who 
repeatedly witness the manipulative and coercive behaviors showed by the perpetrators of family violence can end up developing such behaviors.[36] Consistent with literatures, Van Heugten and Wilson found that criminal behavior and youth aggression were high in youth who had witnessed violence between parents.[37] A boy who had witnessed his mother being abused was ten times more likely to perpetrate IPV against his wife as an adult. $[17,38]$

Our findings also suggested that the children who witness violence between parents are vulnerable to developing PTSD symptoms and addiction behavior. As the primary criteria for PTSD diagnosis is the exposure to extremely threating events[39], authors noted that events that fall in the realm of family violence can include physical or emotional aggression where one parent is a victim and another is a perpetrator.

The actions vary widely in severity, from minor aggression (e.g., pushing, shoving, slapping) to death of a family member which is meaningful and significant of trauma.[40] Relatedly, Hyde-Nolan and Juliao in theory of violence as trauma found that the failure to integrate abuse memories in addition to inability to incorporate the experiences of abuse into structure of large memory led the victims seem to have the tendencies to re-experience the trauma.[41]

According to Hyde-Nolan and Juliao's model, the victims repeat the trauma in their behaviors, physiological and emotions via the neuroendocrine pathways.[42] As with all traumatic events, only a portion of the children who experience violence exposure in their homes will develop PTSD. Authors also noted that alcohol and other drugs may be used by children from violent family to relieve the symptoms of mental problems.[14] Noting that the children were aged 1617 years old in this study, they might have intervened in stopping fight between parents or helping the victims to beat the perpetrator.

Secondly, our findings indicated associations between parental anxious attachment and anxiety and addiction 
symptoms in offspring, and parental avoidant attachment and depression symptoms in offspring. Also both parental low self-esteem and PTSD symptoms were linked with depression symptoms and PTSD symptoms in offspring. Regardless of the impacts of parental family violence, our findings indicated that both parental anxious and avoidant attachment were linked with anxiety, addiction symptoms and depressive symptoms, and parental low-selfesteem were associated with depressive symptoms in offspring.

Consistent with the literature, history of parental mental disorders predisposes offspring to increased rates of depression and other mental health problems when compared to offspring of healthy parents.[43] This is possibly because the mothers are emotionally absent and often unable to care for the children's emotional needs.[44] For example, "mothers who have PTSD tend to be quicker and more impulsive in their actions toward their children and also to underestimate their children's distress".[44] However, Perroud et al. to control anxiety, and high levels of

found that Rwandan women survivors of the 1994 genocide perpetrated against Tutsi could transmit PTSD symptoms to their offspring. Their findings showed that PTSD was associated with epigenetic modifications that similarly found in the mothers and their offspring.[20] The same was shown in a very recent study on epigenetic transmission of PTSD in the Rwandan population. [45]

The findings of this study also indicated that parental anxious and avoidant attachment were linked with anxiety, addiction and depressive symptoms in offspring. In line with our findings, scholars revealed that parental anxious and avoidant attachments were linked to increased internalizing or anxiety symptoms, and substance use in offspring.[46,47] Hazan and Shaver suggested that person's attachment pattern in adulthood is a reflection of his or her attachment history.[48]

As such, attachment insecurity poses an elevated risk for the development of anxiety, the use of cognitive avoidance 
overall pathology.[49] Significant linking parental self-esteem and authors also found that insecure mental disorders in offspring, Small attachment arises more often in found that parent's feeling of selfpopulations of offspring who had been worth were associated with the victims of physical abuse or behaviors he or she employs when neglect.[50,51] Therefore, history of interacting with adolescents and the insecure attachment in infancy child's independence and desire for contributed to emotion regulation great autonomy.[57] These links were difficulties in preschool years, and frequently found to exist in mothers such difficulties were associated with than fathers; more worryingly, anxiety and depressive symptoms in middle childhood.[52,53]

mothers are often identified as the victim of FV.[57]

Scholars for tenets of attachment theory also found that one of the Generally, our findings highlighted that the combination of parental strongest predictors of adolescent substance abuse was the strength of the attachment between the adolescent and his mother.[54,55] Further, an insecure relationship in infancy was associated with negative peer relationship representations in preadolescence, which were associated with an increased anxiety and substance use in adolescence.[56]

Our findings also indicated that parental low self-esteem was so.[58] associated with depression symptoms and PTSD symptoms in offspring. There are some limitations to this Although there is a lack of literature study: This study is limited to its 
cross-sectional design; an inductive and longitudinal design with a high sample can help for good inferences. The assessment of mediators and moderators between parental family violence and mental health problems, and mental disorders in offspring using epigenetic approach is needed for a better understanding of this phenomenon. Further studies also may refine analyses between Family Violence and Psychological Disorders in offspring using ANOVA, MANOVA and Pathways analyses.

Finally, the current study suffers from mono-method bias, as it relies exclusively on self-report measures of psychopathic traits, someone being assessed for violence and psychopathy may not self-report accurately in an attempt to look better. Therefore, future study should benefit from inclusion of Interview-Based Assessment of Antisocial Personality Disorder (ASPD) as defined in DSMIV[59] and in the main diagnostic codes section (II) of DSM-5.[39]

\section{Conclusion}

Overall, the findings of this study highlighted that either parental family violence or parental mental health problems seemed to affect mental health function of offspring. Parental family violence was linked to psychopathy, PTSD symptoms and addiction behavior in offspring.

Moreover, parental anxious and avoidant attachment were linked to anxiety and addiction symptoms, and depression symptoms respectively. The results also indicated that both parental low self-esteem and PTSD symptoms were associated with depression symptoms in offspring and PTSD symptoms in offspring. The above results suggest that the measure of prevention and providing care to mental ill patients from violent families in Rwanda should focus on the treatment of both parental and children mental disorders.

\section{Authors 'contributions}

TU, JN, EH, IM and JM contributed to the conception, design, data analysis and interpretation, and writing of the manuscript. 


\section{Conflict of interest}

The authors confirm that there are no known conflicts of interest associated with this publication and there has been no significant financial support for this work.

This article is published open access under the Creative Commons Attribution-NonCommercialNoDerivatives (CC BYNC-ND4.0). People can copy and redistribute the article only for noncommercial purposes and as long as they give appropriate credit to the authors. They cannot distribute any modified material obtained by remixing, transforming or building upon this article. See https://creativecommons.org/licenses/by-nc-nd/4.0/

\section{References}

1. World Health Organization. Preventing intimate partner and sexual violence against women: taking action and generating evidence. Geneva: World Health Organization; 2010.

2. World Health Organization. Violence against women: a 'global health problem of epidemic proportions'[- News release]. Geneva: World Health Organization; 2013.

3. Mukamana JI, Machakanja P, Adjei NK. Trends in prevalence and correlates of intimate partner violence against women in Zimbabwe, 2005-2015. BMC Int Health Hum Rights
[Internet]. 2020;20:2. Available from:

https://doi.org/10.1186/s1291

4-019-0220-8

4. Uthman OA, Lawoko S, Moradi T. Factors associated with attitudes towards intimate partner violence against women: a comparative analysis of 17 sub- Saharan countries. BMC Int Heal Hum Rights [Internet]. 2009;9:14. Available from: https://doi.org/10. 1186/1472698X-9-14

5. Slegh H, Kimonyo A. Masculinity and gender based violence in Rwanda: Experiences and perceptions of men and women. Kigali, Rwanda: Rwanda Men's Resource; 2010.

6. Mukashema I. A Report About Intimate Partner Violence In Southern And Western Rwanda. Int J Child, Youth Fam Stud. 2017;9:68-99.

7. Eldoseri HM. Intimate partner physical violence against women in Saudi Arabian primary healthcare clinics: Old Dominion University; 2012. 
8. Capaldi DM, Knoble NB, Shortt JW, Kim HK. A Systematic Review of Risk Factors for Intimate Partner Violence. Partner Abuse [Internet].

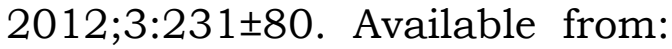
https://doi.org/10.1891/19466560.3.2.231

9. Ellsberg M, Jansen HA, Heise L, Watts $\mathrm{CH}$ G-MC. Intimate partner violence and women's physical and mental health in the WHO multi-country study on women's health and domestic violence: an observational study. Lancet [Internet]. 2008;37. Available from:

https://doi.org/10.1016/s0140 -6736(08)60522-x

10. García-Moreno C, Pallitto C, Devries K, Stöckl H, Watts C, Abrahams N. Global and regional estimates of violence against women: Prevalence and health effects of intimate partner violence and nonpartner sexual violence. Geneva, Switzerland: World Health Organization; 2013.

11. Breet E, Seedat S, Kagee A.
Posttraumatic Stress Disorder and Depression in men and women who perpetrate intimate partner violence. $\mathrm{J}$ Interpers Violence. 2019;34:2181-98.

12. Trevillion K, Oram S, Feder G, Howard LM. Experiences of domestic violence and mental disorders: a systematic review and meta-analysis. PLoS One. 2012;7:e51740.

13. $\mathrm{Yu} \mathrm{R}$, Nevado-Holgado AJ, Molero Y, D'Onofrio BM, Larsson H, Howard LM, et al. Mental disorders and intimate partner violence perpetrated by men towards women: A Swedish population-based longitudinal study. Plos Med [Internet]. 2019;16. Available from: https://doi.org/10.1371/journa 1.pmed.1002995

14. Chan AW, Altman DG. Epidemiology and Reporting of Randomised Trials Published in PubMed Journals. Lancet. 2005;365:1159-62.

15. Carracedo S, Fariña F, Seijo, D. Children exposed to intimate partner violence: impact assessment and guidelines for 
intervention. Rev Psicol Clínica con Niños y Adolesc. 2018;5:1622.

16. $\mathrm{Vu}$ NL, Jouriles EN, McDonald R, Rosenfield D. Children's exposure to intimate partner violence: a meta-analysis of longitudinal associations with child adjustment problems. Clin Psychol Rev. 2016;46:25-33.

17. Gilbert LK, Breiding MJ, Merrick MT, Parks SE, Thompson WW, Dhingra SS, Ford DC. Childhood Adversity and Adult Chronic Disease: An update from ten states and the District of Columbia, 2010. Am J Prev Med. 2015;48:345-9.

18. Kitzmann KM, Gaylord NK, Holt AR KE. Child witness to domestic violence: A metaanalytic review. J Consult Clin Psychol. 2003;71:339-52.

19. Groves B. Mental health services for children who witness domestic violence.

Domest Violence Child. 24.
1999;9:122-30.

20. Perroud N, Rutembesa E, Paoloni-Giacobino E, Mutabaruka J, Mutesa L, Stenz
L, Malafosse A, Karege F. The Tutsi genocide and transgenerational transmission of maternal stress: epigenetics and biology of the HPA axis. World J Biol Psychiatry. 2014;Early onli:1-12.

21. Olaya B, Ezpeleta L, Osa N, Granero J, Doménech $\mathrm{M}$. Mental health needs of children exposed to intimate partner violence seeking help from mental health services. Child Youth Serv Rev. 2010;1004-11.

22. Limiñana AR, Suriá $R$, Mateo MA. Child behaviour problems and parenting skills of mothers in environments of intimate partner violence. Adv online Publ. 2017;

23. Brook JS, Whiteman M, Gordon AS, Cohen P. Dynamics of childhood and adolescent personality traits and adolescent drug use. Dev Psychol. 1986;22:403-414.

Cooper ML, Shaver PR, Collins NL. Attachment styles, emotion regulation, and adjustment in adolescence. J Pers Soc Psychol [Internet]. 1998;74:1380-97. 
Available

https://doi.org/10.1037/0022-

3514.74.5.1380

25. Daniel WW. Biostatistics: A 31 Foundation for Analysis in the Health Sciences. 7th ed. New York: John Wiley \& Sons; 1999.

26. Rosenberg M. Society and the adolescent self-image. Princeton,. Princeton University Press; 1965.

27. Foa EB, Capaldi S. Manual for the Administration and Scoring of the PTSD Symptom ScaleInterview for DSM-5 (PSS-I-5). 2013.

28. Wei M, Russell DW, Mallinckrodt B, Vogel, DL. The Experiences in Close Relationship Scale (ECR)-Short Form: Reliability, Validity, and Factor Structure. J Pers Assess. 2007;88:187-204.

29. Weissman MM, Orvaschel H, Padian N. No. J Nerv Ment Dis. 1980;168:736-740.

30. Benning SD, PatrickC J, Hicks BM, Blonigen DM, Krueger, RF. Factor structure of the Psychopathic Personality Inventory: Validity and implications for clinical assessment. Psychol Assess. 2003; 15:340-50.

Henry-Edwards S, Humeniuk R, Ali R, Poznyak V MM. The Alcohol, Smoking and Substance Involvement Screening Test (ASSIST): Guidelines for Use in Primary Care. Geneva: World Health Organization; 2003.

32. Birmaher B, Khetarpal S, Cully M, Brent D, Mckenzie S. Screen for Child Anxiety Related Disorders (SCARED) CHILD Version. Western Psychiatric Institute and Clinic, University of Pittsburgh; 1995.

33. Patrick C. Conceptualizing Psychopathy in Terms of Boldness, Meanness, \& Disinhibition: Implications for Prevention \& Treatment. Florida State University; 2011.

34. Sica C, Drislane L, Caudek C, Angrill A, Bottesi G, Cerea S, Ghisi M. A test of the construct validity of the Triarchic Psychopathy Measure in an Italian community sample). Pers Individ Dif. 2015;82:Pers. 
Individ. Dif.

35. Brislin RW. Back-translation for cross-cultural research. J Cross Cult Psychol. 1970;1:185-216.

36. Leedom LJ. The Impact of Psychopathy on the Family. IntechOpen. 2017;

37. Van Heugten K, Wilson E. Witnessing intimate partner violence: Review of the literature on coping in young persons. Canterbury: University of Canterbury; 2016.

38. Vargas L, Cataldo J DS. Domestic Violence and Children(link is external). In G.R. Walz \& R.K. Yep (Eds.), VISTAS: Compelling

Perspectives on Counseling. Alexandria: American

Counseling Association; 2005.

39. American Psychiatric Association. Diagnostic and statistical manual of mental disorders. 5. Association., American Psychiatric,; 2013.

40. Margolin G, Vickerman K. Posttraumatic stress in children and adolescents exposed to family violence: I. Overview and issues. Prof Psychol Pract.
2007;38:613-9.

41. Hyde-Nolan ME, juliao $T$. Theoretical Basis for Family Violence. Ontario: Jones and Bartlett Learning; 2012.

42. Van der Kolk BA, Saporta J. The biological response to psychic trauma: mechanisms and treatment of intrusion and numbing. Anxiety Res (ISSN 0891-7779). 1991;4:199-212.

43. Behere AP, Basnet P, Campbell P. Effects of Family Structure on Mental Health of Children: A Preliminary Study. Indian $\mathrm{J}$ Psychol Med. 2017;39:457-463.

44. Chemtob CM, Carlson JG. Psychological effects of domestic violence on children and mothers. Int $\mathrm{J}$ Stress Manag. 2004;11:209-226.

45. Rudahindwa S, Mutesa L, Rutembesa E , Mutabaruka J, Qu A, Wildman DE, Jansen S, Uddin M. Transgenerational effects of the genocide against the Tutsi in Rwanda: A posttraumatic stress disorder symptom domain analysis. AAS Open Res [Internet]. 2020; Available from: 
https://doi.org/10.12688/aaso penres. 12848.2

46. Goldberg S, Gotowiec A, Simmons RJ. Infant-mother attachment and behavior problems in healthy and chronically ill preschoolers. Dev Psychopathol. 1995;7:267-282.

47. Roelofs J, Meesters C, Ter Huurne M, Bamelis L, Muris P. On the links between attachment style, parental rearing behaviors, and internalizing and externalizing problems in non-clinical children. J Child Fam Stud. 2006;15:331-344.

48. Hazan C, Shaver PR. Original attachment three category measure [Internet]. 1987 [cited 2017 Jan 20]. Available from: http://psychology.ucdavis.edu/ labs/Shaver/measures.htm.

49. Wedekind D, Bandelow B, Heitmann $\mathrm{S}$ et al. Attachment style, anxiety coping, and personality-styles in withdrawn alcohol addicted inpatients. Subst Abus Treat Prev Policy. 2013;8.

50. Carlson V, Cicchetti D, Barnett
D, Braunwald $\quad$ K. Disorganized/Disoriented Attachment Relationships in Maltreated Infants. Dev Psychol [Internet]. 1989;25:525-31. Available from: https://doi.org/10.1037/00121649.25.4.525

51. Bowlby J. Violence in the family as a disorder of the attachement and caregiving systems. Am J Psychoanal. 1984;44:9-27.

52. Bosquet $M$, Egeland B. The development and maintenance of anxiety symptoms from infancy through adolescence in a longitudinal sample. Dev Psychopathol. 2006;18:517550.

53. Niyonsenga J, Mutabaruka J. Factors of postpartum depression among teen mothers in Rwanda: a cross- sectional study. Psychosom J Gynecol Obstet [Internet]. 2020; Available from: https://doi.org/10.1080/01674 82X.2020.1735340

Sedlak AJ, Mettenburg J, Basena M, Petta I, McPherson K, Greene A, Li S. Fourth 
National Incidence Study of 57. Small SA. Parental Self-Esteem Child Abuse and Neglect (NIS- and Its Relationship to 4): Report to Congress, Childrearing Practices, ParentExecutive Summary.

Washington, DC: U.S. Adolescent Interaction, and Department of Health and Adolescent Behavior. J Marriage Human Services, 58.

Administration for Children and Families;

55. Litrownik AJ, Runyan DK, Bangdiwala SI, Margolis B, Kotch JB. Importance of Early Neglect for Childhood Aggression. Pediatrics. 2008;121:725-31.

56. Brumariu LE KKA. Mother-child 59. attachment and social anxiety symptoms in middle childhood. J Appl Dev Psychol. 2008;393402.

Fam. 1988;50:1063-72.

Silvern L, Karyl J, Waelde L, Hodges WF , Starek J, Heidt E, Min K. Retrospective Reports of Parental Partner Abuse: Relationships to Depression, Trauma Symptoms and SelfEsteem Among College Students. J Fam Violence. 1995;10.

American Psychiatric Association. Diagnostic and statistical manual of mental disorders. 4. Washington, DC: American Psychiatric Association; 2000. 